\title{
The Association of Obstructive Sleep Apnea and Nocturnal Hypoxemia with Lipid Profiles in a Population-Based Study of Community-Dwelling Australian Men
}

\author{
Layla B Guscoth (1D) \\ Sarah L Appleton $\mathbb{D}^{2}$ \\ Sean A Martin' \\ Robert J Adams (iD ${ }^{2}$ \\ Yohannes A Melaku (iD) ${ }^{2}$ \\ Gary A Wittert'
}

'Freemasons Centre for Male Health and Well-Being, South Australian Health and Medical Research Institute and Faculty of Health and Medical Sciences, University of Adelaide, Adelaide, South Australia, 5000, Australia; ${ }^{2}$ Flinders Health and Medical Research Institute (Sleep Health, Formerly the Adelaide Institute for Sleep Health) A Flinders Centre of Research Excellence, Flinders University, Adelaide, South Australia, 5042, Australia
Correspondence: Sarah L Appleton Flinders Health and Medical Research Institute (Sleep Health, formerly the Adelaide Institute for Sleep Health) A Flinders Centre of Research Excellence, Flinders University, Bedford Park, Adelaide, South Australia, 5042, Australia Email sarah.appleton@flinders.edu.au
Objective: To determine the association of obstructive sleep apnea and nocturnal hypoxemia with serum lipid profiles in unselected community-dwelling men.

Methods: Cross-sectional data from participants of the Men Androgen Inflammation Lifestyle Environment and Stress (MAILES) study ( $\mathrm{n}=753)$ who underwent full in-home polysomnography (Embletta X100) was used. Triglycerides, high- (HDL), low-density lipoprotein (LDL), and total cholesterol were assessed on a fasting morning blood sample. Multivariable linear regression analyses assessed associations between lipids and continuous measures of nocturnal hypoxemia (oxygen desaturation index (3\%) (ODI), apnea-hypopnea index (AHI), and rapid eye movement sleep apnea-hypopnea index (REM-AHI)), adjusted for chronic conditions, risk behavior and sociodemographic factors. Sensitivity analyses examined the effect of lipid lowering therapies on reported estimates. Effect modification was examined through stratification by waist circumference groups.

Results: In 753 participants with mean (SD) age of 60.8 (10.9) years and waist circumference: $99.3(11.6) \mathrm{cm}$, the prevalence of OSA (AHI $\geq 10)$ was $52.6 \%$. Overall, no significant associations between OSA metrics and lipid measures were found. Similarly, sensitivity analysis excluding lipid lowering therapies showed no significant associations. In analysis stratified by waist circumference $(<95 \mathrm{~cm}, 95-100 \mathrm{~cm},>100 \mathrm{~cm})$, ODI $(3 \%$, unstandardized B: 0.027, 95\% CI: 0.015-0.040), AHI (0.023, 0.012-0.033) and $\mathrm{AHI}_{\text {REM }}(0.012,0.001-0.022)$ were positively associated with serum triglycerides in participants with a normal waist circumference $(<95 \mathrm{~cm})$.

Conclusion: Obstructive sleep apnea metrics were positively associated with serum triglyceride levels in men with a normal waist circumference. Healthy weight individuals with OSA require clinical attention to improve cardiometabolic risk profiles.

Keywords: obstructive sleep apnea, triglycerides, hypoxemia, cohort studies, men, visceral obesity

\section{Introduction}

Obstructive sleep apnea (OSA) is a syndrome characterized by partial or complete obstruction of the upper airways, resulting in intermittent hypoxia, variably accompanied by sleep fragmentation and daytime sleepiness. ${ }^{1}$ In male participants of the Swiss HypnoLaus cohort, the prevalence of moderate-to-severe OSA was $49.7 \%{ }^{2}{ }^{2}$ with $74.7 \%$ men aged 40 or over having OSA syndrome according to ICD-3 criteria. $^{3}$ However, OSA is often underdiagnosed and unrecognized in clinical 
settings. ${ }^{4}$ OSA has been implicated in the development of cardiovascular conditions, ${ }^{5}$ however OSA during rapid eye movement (REM) sleep and the resultant nocturnal hypoxemia are also longitudinally associated with cardiovascular disease $^{6}$ and associated risk factors such as hypertension, ${ }^{7}$ insulin resistance, ${ }^{8}$ metabolic syndrome, ${ }^{9}$ and carotid atherosclerosis. $^{10}$ Animal models suggest that this increased cardiovascular risk is the result of intermittent hypoxemia ${ }^{11}$ leading to activation of the sympathetic nervous system, increased oxidative stress ${ }^{12}$ and systemic inflammation. $^{13,14}$ Furthermore, chronic intermittent hypoxia $(\mathrm{CIH})$ reduced clearance of triglyceride-rich lipoproteins and inhibited adipose tissue lipoprotein lipase activity. $^{15}$

Current studies investigating an association between OSA and dyslipidemia have shown inconsistent results. ${ }^{16-18}$ This variation may be due to differences in study populations, the use of polygraphy rather than polysomnography, which may underestimate OSA, and studies largely conducted in the clinical setting which may not be generalizable to community-based, non-clinical samples. In a large clinical sample of adults being investigated for OSA, Trzepizur et $\mathrm{al}^{19}$ showed a relationship between oxygen desaturation index (ODI) with higher triglycerides and lower HDL. In the European Sleep Apnea Database Cohort (ESADA), hyperlipidemia was independently associated with $\mathrm{ODI}^{20}$ and a positive relationship between triglyceride concentration and both ODI and AHI were shown. ${ }^{21} \mathrm{~A}$ recent study also showed an independent association between severe OSA (AHI $\geq 30 / \mathrm{h}$ ) with dyslipidemia, total cholesterol and LDL cholesterol, with ODI shown to be an independent determinant of triglyceride levels. ${ }^{22}$ In a general population sample, HypnoLaus Study investigators found that OSA was an independent risk factor for incident metabolic syndrome mediated through increased nocturnal hypoxemia, however no associations with incident metabolic syndrome components including high triglyceride or low HDL levels were seen. ${ }^{23}$

Given the paucity of community-based studies, we aimed to determine the association between polysomnography-measured OSA parameters and nocturnal hypoxemia with serum lipid concentrations in a community dwelling cohort $(n=753)$ of adult males. Communitybased studies are required which can identify atypical/ asymptomatic OSA in individuals perceived to be at low risk of OSA and its associated cardiometabolic sequelae in those who are less likely to be referred for a sleep study. We hypothesize that given that central obesity is a strong risk factor for both $\mathrm{OSA}^{24}$ and dyslipidemia, it may overwhelm any contribution of nocturnal hypoxemia to dyslipidemia. A few small clinical studies report lipid alterations in patients with OSA free of generalized obesity $^{23}$ or with both normal BMI and normal waist circumference levels. ${ }^{25,26}$ Supporting this, a recent study using early morning $3-\mathrm{T}-{ }^{1} \mathrm{H}$-magnetic resonance spectroscopy of the vastus lateralis muscle in men reported substantial and most likely transient increases of intramyocellular and extramyocellular lipids in non-obese men with OSA compared to participants without OSA. ${ }^{27}$ Consequently, we conducted analyses stratified by waist circumference to observe an obesity-independent association between OSA metrics and dyslipidemia.

\section{Materials and Methods \\ Study Participants}

Participants were from the Men Androgens Inflammation Lifestyle Environment and Stress Study (MAILES study, $\mathrm{n}=2563$ at baseline), a longitudinal study of communitydwelling men participating in the North West Adelaide Health Study (NWAHS) and Florey Adelaide Male Aging Study (FAMAS). Participants were aged at least 35 years at baseline (2002-2006) and are of predominantly European or Australian descent $(96 \%)$ as previously described. ${ }^{28}$ MAILES participants underwent a computerassisted telephone health interview (CATI) in 2010 ( $\mathrm{n}=1629$ ), and men who did not report a previous diagnosis of OSA on a sleep study ( $\mathrm{n}=1445)$ were invited to take part in a sub-study including polysomnography with $75.2 \%$ agreeing. In $2010-11,837$ men successfully completed eight-channel in-home unattended polysomnography (PSG, Embletta X100, Embla Systems, Broomfield, CO, USA) which measured EEG, EOG, EMG, nasal pressure, thoracic and abdominal effort, oximetry, and body position. Trained staff visited study participants in their homes to set up the PSG equipment. The Pittsburgh Sleep Quality Index ${ }^{29}$ and the Epworth Sleepiness Scale ${ }^{30}$ were administered, and all current medications were recorded. Sleep study participants showed minor healthy volunteer bias but did not differ in sleep symptoms compared to nonsleep study participants. ${ }^{28}$

Sleep studies were manually scored by a single, trained sleep technician according to American Academy of Sleep Medicine 2007 alternate criteria (hypopnea defined by a > $50 \%$ decrease in nasal pressure (or in both thoracic and abdominal excursions) with an associated 3\% oxygen 
desaturation or an EEG arousal) and recommended for use in prospective epidemiological studies by the AASM and by an expert panel of the Australasian Sleep Association. ${ }^{31}$ Independent variables included the apnea-hypopnea index (AHI), rapid eye movement sleep $\mathrm{AHI}\left(\mathrm{AHI}_{\mathrm{REM}}\right.$, in participants recording at least 30 minutes of REM sleep), ${ }^{7}$ $\mathrm{AHI}_{\text {REM }}$ if $\mathrm{AHI}_{\mathrm{NREM}}<10$, and oxygen desaturation index (ODI, 3\%). OSA was defined as $\mathrm{AHI} \geq 10 / \mathrm{h}$ of sleep, with further categorization into mild (AHI 10-19/h sleep), moderate (20-29/h sleep) or severe ( $\geq 30 / \mathrm{h}$ sleep) as defined by the alternate 2007 AASM definition. ${ }^{32}$ The cut-offs for classification were chosen because Ruehland et $\mathrm{al}^{32}$ have shown that an AHI of $5 / \mathrm{h}$ of sleep used to define sleepdisordered breathing scored by the 2007 recommended AASM criteria is equivalent to an AHI of $10 / \mathrm{h}$ of sleep using the alternate AASM definition, and 15/h using the older 1999 Chicago criteria. In order to maintain comparability with previous work a cut-off of $10 /$ h was chosen. $^{32}$

The study was conducted in accordance with the Declaration of Helsinki. Study approval was provided by the research ethics committees at the Royal Adelaide Hospital and North West Adelaide Health Service (approval numbers: 2010054, 02305H). Written, informed consent was obtained from all participants.

\section{Dependent Variables}

Lipid measurements were obtained at clinical assessments between 2007 and 2010 on a fasting blood sample taken between $8 \mathrm{am}$ and $11 \mathrm{am}$ after a 12 hour fast. Total cholesterol, triglycerides, HDL (high-density lipoprotein), LDL (low-density lipoprotein), glucose and HbA1c were quantified by an Olympus AU5400 automated chemistry analyzer $^{28}$ in two laboratories of the South Australian Department of Health pathology service.

\section{Cardiovascular Risk Factors}

Clinic assessment (as previously described) ${ }^{28}$ included anthropometry and blood pressure. Body mass index (BMI, $\mathrm{Kg} / \mathrm{m}^{2}$ ) was categorized by World Health Organization criteria of underweight/normal $<24.9$, overweight 25.0-29.9 and obese $\geq 30.0$. Systolic and diastolic blood pressures were taken using a standard calibrated sphygmomanometer, with two measurements taken 5 to 10 minutes apart and the mean result calculated. A definition of systolic blood pressure $>140 \mathrm{mmHg}$ and diastolic blood pressure $>90 \mathrm{mmHg}$ or the use of antihypertensive medication was used to define hypertension. The presence of cardiovascular disease (including myocardial infarction, stroke, transient ischemic attack, angina) was identified via self-reported questionnaire. The presence of diabetes was defined by a doctor's diagnosis, $\mathrm{HbA} 1 \mathrm{c} \geq 6.5 \%$, fasting glucose $\geq 7.0 \mathrm{mmol} / 1$ or use of anti-diabetic medications.

\section{Other Covariates}

Socioeconomic factors including age, gender, marital status, country of birth, highest education level and gross household income were obtained by CATI or selfcompleted questionnaire. Behavioral risk factors including smoking status and alcohol consumption were identified using a self-reported questionnaire and physical activity was assessed with the Active Australia questionnaire. ${ }^{33}$ Current use of psychotropic agents (benzodiazepines, opiates, anti-psychotics, anti-depressants) and other sleep disrupting medications (nicotine replacement therapy) was identified on the night of the sleep study by staff. ${ }^{28}$ Lipid lowering therapies were classified using the ATC classification system ${ }^{34} \mathrm{C} 10 \mathrm{~A}$ included plain lipid modifying agents (HMG-CoA reductase inhibitors, fibrates, bile acid sequestrants, nicotinic acid and derivatives, other lipid modifying agents) and $\mathrm{C} 10 \mathrm{~B}$ combinations of lipid modifying agents (HMG-CoA reductase inhibitors in combination with other lipid modifying agents). Depression was assessed using the 20-point Centre for Epidemiological Studies Depression Scale (CES-D) for NWAHS participants $^{35}$ and the Beck Depression Inventory (BDI1A) for FAMAS participants. ${ }^{36}$

Principal component analysis was used to identify dietary patterns using data collected by a validated food frequency questionnaire. We identified two dietary patterns western and prudent dietary patterns. ${ }^{37}$ A prudent dietary pattern is based on high dietary intake of vegetables, fruit, fish, whole grains, legumes. A western dietary pattern is based on high intake of red meat, processed meat, refined grains. ${ }^{38}$ We then used a single diet construct, derived by subtracting factor scores of prudent patterns from western pattern. A higher diet score represents higher adherence to a healthy diet. ${ }^{39}$

\section{Statistical Analysis}

Statistical analysis was conducted using SPSS version 24 (IBM corporation, Armonk, NY USA). The analytical sample is described as mean $\pm \mathrm{SD}$ or median and interquartile range (IQR) for continuous variables and $n(\%)$ for categorical variables and tests for differences across waist circumference categories included Student's $t$-test, 
independent samples Kruskal-Wallis test and Pearson chisquare tests, respectively. Statistical significance was set at $\mathrm{p}<0.05$. Those using psychotropic agents (benzodiazepines, opiates, anti-psychotics, anti-depressants) and other medications that disrupt sleep (nicotine replacement therapy) were excluded $(n=84)$ from the analysis. The selection of the analytical sample $(n=753)$ is shown in a CONSORT diagram (Figure 1).

Linear regression analysis identified unadjusted, and covariate adjusted relationships between sleep parameters including $\mathrm{AHI}, \mathrm{AHI}_{\mathrm{REM}}$ (in participants recording at least 30 minutes of REM sleep), $\mathrm{AHI}_{\mathrm{REM}}$ if $\mathrm{AHI}_{\mathrm{NREM}}<10$, ODI $(3 \%)$ and lipid measures (Model 1). Separate models determined the association between sleep parameters and lipid measures, adjusted for age, waist circumference, smoking (non/former compared with current), alcohol (non-low risk compared with moderate-very high risk), total sleep time, diet, depressive symptoms (none compared with at least mild depression) and HbA1c (Model 2). We checked for collinearity and homoscedastic assumptions. Waist circumference was used rather than BMI due to evidence that it is a better predictor of cardiovascular risk compared to BMI. ${ }^{40}$

We further conducted a sensitivity analysis to exclude participants on lipid-lowering therapies. Given the effects of obesity on OSA and lipid levels, we further explored the relationship between triglycerides

\section{MAILES-3 (2010)}

Computer-assisted telephone interview $(n=1629)$

PSG eligibility $n=1445$ without prior OSA diagnosis

PSG volunteers $n=1087$
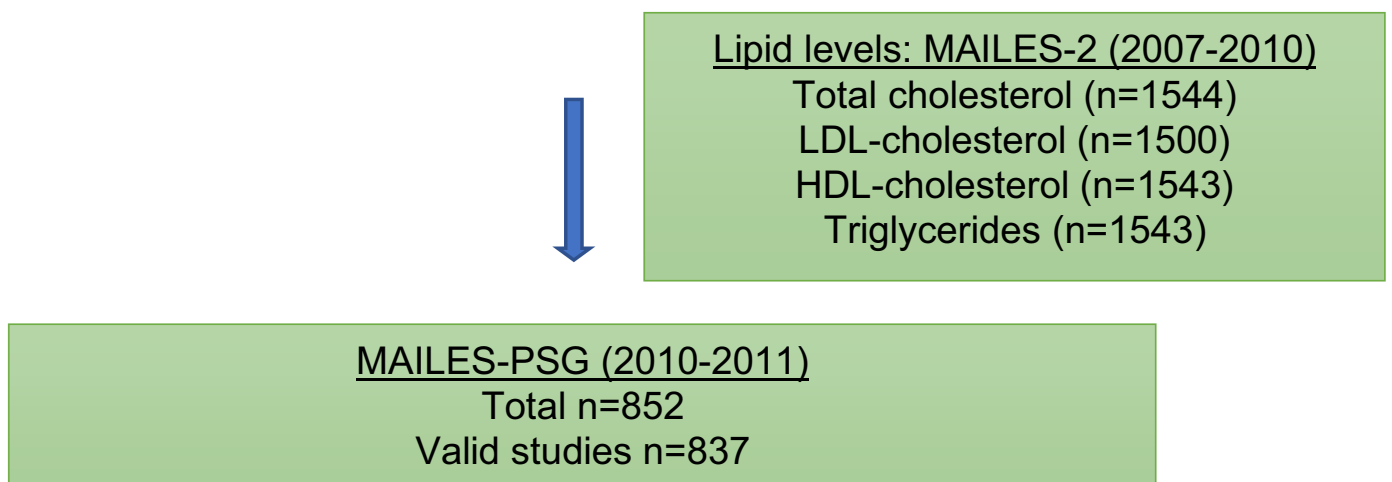

Valid studies $n=837$

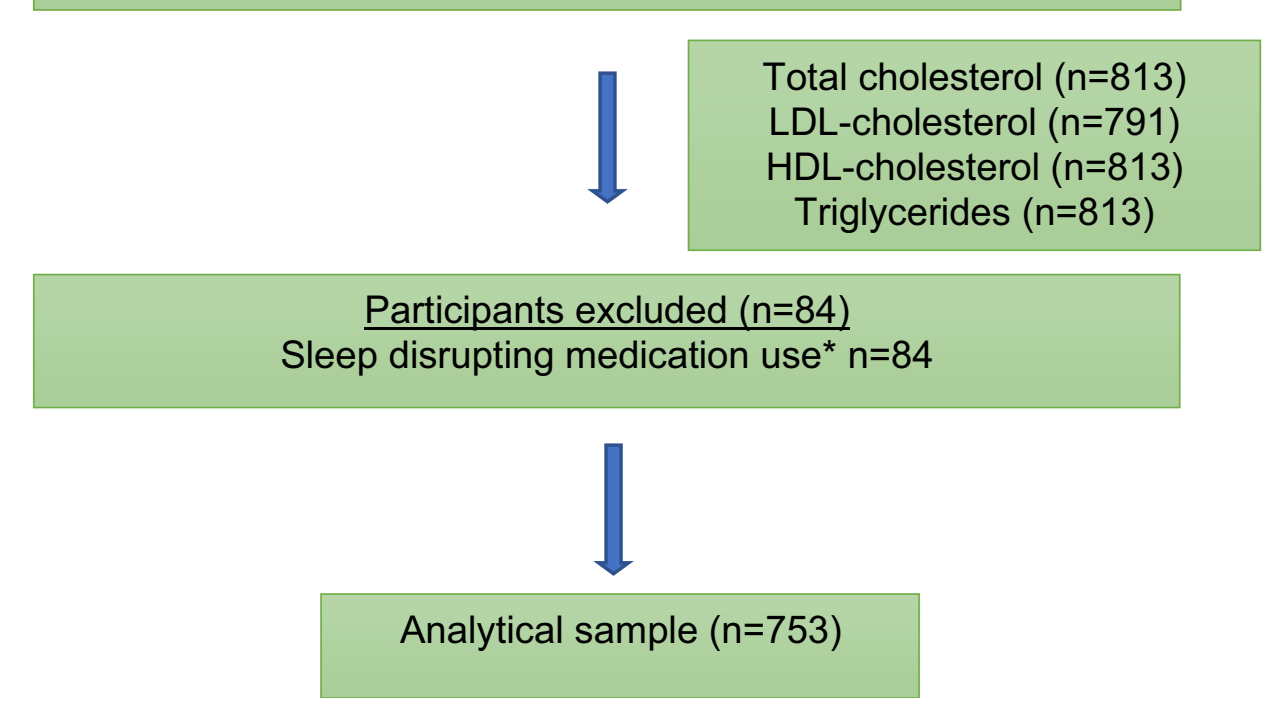

Figure I Flow diagram of the MAILES study participants. *Sleep-disrupting medications include benzodiazepines, opiates, nicotine replacement therapy, anti-psychotics, antidepressants. 
and $\mathrm{AHI}, \mathrm{AHI}_{\mathrm{REM}}, \mathrm{AHI}_{\mathrm{REM}}$ if $\mathrm{AHI}_{\mathrm{NREM}}<10$, and $\mathrm{ODI}$ $(3 \%)$, stratified by waist circumference $<95 \mathrm{~cm}$, 95 $100 \mathrm{~cm}$ and over $100 \mathrm{~cm}$. Triglycerides were specifically analyzed due to a strong relationship between waist circumference and triglycerides, likely mediated through insulin resistance ${ }^{41}$ and due to the minimal effects of lipid lowering therapies compared to other lipid measures. We further conducted binary logistic regression to determine associations between clinical categories of OSA [no OSA $<10 / \mathrm{hr}$, mild $(10-19 / \mathrm{hr})$, moderate (20$29 / \mathrm{hr})$ and severe $(\geq 30 / \mathrm{hr})$ (27)] and the categorized dependent variable - triglyceride $(\geq 1.7 \mathrm{mmol} / \mathrm{L})$. Covariates were the same as for the linear regression models.

\section{Results}

\section{Participant Characteristics and Sleep Measures}

The sociodemographic and sleep characteristics of the analyzed sample overall and by OSA severity category are shown in Table 1. The mean (SD) age was 60.8 (10.9) years and waist circumference $99.3(11.6) \mathrm{cm}$. The prevalence of diabetes was $17.1 \%$ and hypertension was $55.4 \%$. Undiagnosed OSA (AHI $\geq 10 / \mathrm{hr}$ ) was determined in $52.6 \%$ of participants, with severe OSA (AHI $\geq 30 / \mathrm{h}$ ) present in $12.4 \%$. The characteristics of the sample in relation to waist circumference levels are shown in Supplementary Table 1.

\section{Relationship Between Sleep Study Metrics and Lipids}

Covariate unadjusted and adjusted analyses showed no significant associations of $\mathrm{AHI}, \mathrm{AHI}_{\mathrm{REM}}$, REM sleep predominant $\mathrm{AHI}\left(\mathrm{AHI}_{\mathrm{REM}}\right.$ if $\left.\mathrm{AHI}_{\mathrm{NREM}}<10\right)$, or ODI with lipid measures (Table 2).

\section{Relationship Between Sleep Study Metrics and Lipids in Sample Free from Lipid Lowering Therapies}

In a sensitivity analysis $(n=566)$, excluding participants using lipid lowering therapies (Table 3), there was no associations between ODI, AHI, $\mathrm{AHI}_{\text {REM }}$, or REM sleep predominant $\mathrm{AHI}\left(\mathrm{AHI}_{\mathrm{REM}}\right.$ if $\mathrm{AHI}_{\mathrm{NREM}}<10$ ) with lipid measures in co-variate unadjusted or adjusted analyses.
Relationship Between Sleep Study Metrics and Triglycerides, Stratified by Waist

\section{Circumference}

In analysis stratified by waist circumference to minimize the contribution of obesity to hypertriglyceridemia, triglyceride levels were positively associated with AHI, ODI and REMAHI in participants with a waist circumference of $<95 \mathrm{~cm}$ (Figure 2) in co-variate adjusted analyses $(p<0.05)$. Associations were not observed in participants with a waist circumference of $95-100 \mathrm{~cm}$ or $>100 \mathrm{~cm}$. When we considered $\mathrm{AHI}_{\text {REM }}$ in participants with $\mathrm{AHI}_{\text {NREM }}<10$, the association with triglyceride levels did not persist in men with waist circumference $<95 \mathrm{~cm}$ [unstandardized $\mathrm{B}$ (SE) $=0.004$ (0.008), $\mathrm{p}=0.60, \mathrm{n}=147]$. The results remained unchanged in men with waist circumference $95-100 \mathrm{~cm}[-0.029(0.016)$, $\mathrm{p}=0.076, \mathrm{n}=47]$ and waist circumference $>100 \mathrm{~cm}[0.003$ (0.009), $\mathrm{p}=0.75, \mathrm{n}=118]$.

In analyses based on clinical categories of OSA and triglycerides, in males with a waist circumference $<95 \mathrm{~cm}$, severe OSA was significantly associated with an increased likelihood of triglyceride levels $\geq 1.7 \mathrm{mmol} / \mathrm{L} \quad[\mathrm{OR}=4.1$ (95\% CI: 1.1-15.5, $\mathrm{p}=0.039$ )]. For men with moderate OSA, there was an increased likelihood that did not reach statistical significance $[\mathrm{OR}=2.1 \quad(95 \% \mathrm{CI}: 0.7-5.9$, $\mathrm{p}=0.17)]$. Consistent with the findings of the linear regression analysis, there were no associations of severe OSA with triglyceride $\geq 1.7 \mathrm{mmol} / \mathrm{L}$ in men with waist circumference levels of $95-100 \mathrm{~cm}[\mathrm{OR}=0.9(95 \%$ CI: $0.2-4.1$, $\mathrm{p}=0.84)]$ and $>100 \mathrm{~cm} \quad[\mathrm{OR}=0.7 \quad(95 \% \quad \mathrm{CI}: \quad 0.4-1.5$, $\mathrm{p}=0.40)]$.

\section{Discussion}

These data show that in a large, extensively characterized cohort of community dwelling men with a mean age of 61 years, after adjustment for covariates, there was no overall significant relationship between any measure of OSA metrics and serum lipid profiles. However, after stratification by waist circumference, $\mathrm{AHI}$, ODI and $\mathrm{AHI}_{\mathrm{REM}}$ were significantly and positively associated with serum triglyceride concentrations only in men without central adiposity.

OSA during REM sleep is characterized by longer obstructive events, with greater oxygen desaturations ${ }^{42}$ and there is an increasing body of evidence ${ }^{43,44}$ suggesting that compared to obstructive events during non-REM sleep, events during REM sleep may be more harmful. REM-predominant OSA has been associated with incident 
Table I Demographic, Socioeconomic, Cardiometabolic Conditions, and Sleep Parameters of Study Sample

\begin{tabular}{|c|c|c|c|c|c|}
\hline $\begin{array}{l}\text { Participant Characteristics }(n=753) \\
\text { Mean } \pm \text { SD }\end{array}$ & Overall & $\begin{array}{c}A H I<10 / h r \\
n=357\end{array}$ & $\begin{array}{c}\text { AHI I0-19/hr } \\
\quad n=196\end{array}$ & $\begin{array}{l}\text { AHI } 20-29 / \mathrm{hr} \\
\mathrm{n}=107\end{array}$ & $A H I \geq 30 / h r n=93$ \\
\hline Age & $60.8 \pm 10.9$ & $58.9 \pm 10.5$ & $62.1 \pm 10.8$ & $62.9 \pm 10.3$ & $62.9 \pm 11.6$ \\
\hline BMI & $28.6 \pm 4.3$ & $27.7 \pm 3.8$ & $28.5 \pm 4.1$ & $29.4 \pm 4.1$ & $31.5 \pm 5.3$ \\
\hline Waist Circumference & $99.3 \pm 11.6$ & $97.0 \pm 11.3$ & $99.2 \pm 11.8$ & $102.1 \pm 11.3$ & $106.1 \pm 12.0$ \\
\hline Triglycerides & $1.73 \pm 1.64$ & $1.68 \pm 0.93$ & $1.77 \pm 2.8$ & $1.76 \pm 0.97$ & $1.77 \pm 0.89$ \\
\hline Total Cholesterol & $5.22 \pm 1.10$ & $5.25 \pm 1.04$ & $5.21 \pm 1.22$ & $5.21 \pm 1.1$ & $5.06 \pm 1.13$ \\
\hline HDL & $1.32 \pm 0.32$ & $1.32 \pm 0.30$ & $1.36 \pm 0.33$ & $1.28 \pm 0.36$ & $1.26 \pm 0.30$ \\
\hline LDL & $3.15 \pm 0.93$ & $3.21 \pm 0.90$ & $3.20 \pm 0.99$ & $3.15 \pm 0.93$ & $3.04 \pm 0.96$ \\
\hline $\mathrm{HbAlc}$ & $5.9 \pm 0.8$ & $5.8 \pm 0.66$ & $5.9 \pm 0.8$ & $5.9 \pm 0.9$ & $6.0 \pm 1.0$ \\
\hline \multicolumn{6}{|l|}{ Household Income, n (\%) } \\
\hline Up to $\$ 40,000$ & $210(28.6)$ & $83(23.8)$ & $58(30.1)$ & $37(35.2)$ & $32(36.4)$ \\
\hline$\$ 40,00 \mathrm{I}-\$ 80,000$ & $256(34.9)$ & $124(35.5)$ & $66(34.2)$ & $31(29.5)$ & $35(39.8)$ \\
\hline Over $\$ 80,000$ & $234(31.8)$ & $123(35.2)$ & $60(31.1)$ & $33(31.4)$ & $18(20.5)$ \\
\hline Not stated & $35(4.8)$ & $19(5.4)$ & $9(4.7)$ & $4(3.8)$ & $3(3.4)$ \\
\hline \multicolumn{6}{|c|}{ Cardiometabolic Risk Factors and Conditions, n (\%) } \\
\hline Current Smoking $(n=736)$ & $112(15.2)$ & $61(17.4)$ & $21(10.9)$ & $21(20.0)$ & $9(10.3)$ \\
\hline Alcohol Risk: Intermediate- High & $(5.5)$ & $15(4.2)$ & $17(8.7)$ & $6(5.7)$ & $3(3.2)$ \\
\hline Cardiovascular Disease* & $62(8.2)$ & $22(6.2)$ & $14(7.1)$ & $16(15.0)$ & $10(10.8)$ \\
\hline Physical activity level: Sedentary & $56 I(77.2)$ & $77(22.4)$ & $4 I(21.4)$ & $23(22.1)$ & $25(28.5)$ \\
\hline Hypertension & $403(55.4)$ & $164(46.9)$ & III (58.7) & $72(68.6)$ & $56(67.5)$ \\
\hline Diabetes & $127(17.1)$ & $44(12.4)$ & $42(21.6)$ & $16(15.2)$ & $25(28.4)$ \\
\hline $\mathrm{BMI}>30$ & $252(33.7 \%)$ & $85(23.8)$ & $64(32.7)$ & $48(44.9)$ & $55(59.1)$ \\
\hline Waist circumference $>102 \mathrm{~cm}$ & $291(39.9 \%)$ & $76(21.6)$ & $72(38.3)$ & $56(53.3)$ & $55(66.3)$ \\
\hline \multicolumn{6}{|c|}{ Polysomnography Measures, Median (IQR) } \\
\hline Apnoea-Hypopnea Index (AHI) & $10.4(5.7,20.6)$ & $5.5(3.2,7.9)$ & $14.2(119,16.8)$ & $24.2(21.9-26.8)$ & $41.9(35.2,50.7)$ \\
\hline$A H I_{\text {NREM }}$ & $9.6(4.6,20.1)$ & $4.3(2.2,6.7)$ & $13.6(10.6,16.5)$ & $24.3(20.7,27.5)$ & $43.4(35.5,53.1)$ \\
\hline $\mathrm{AHI}_{\mathrm{REM}}{ }^{\ddagger}$ & $14.0(6.3,25.6)$ & $8.1(4.9,15.9)$ & $16.5(9.0,26.1)$ & $24.5(11.5-35.0)$ & $36.7(24.8,58.3)$ \\
\hline Oxygen Desaturation Index & $8.0(3.7,16.1)$ & $3.7(2.1,6.0)$ & II.5 (8.4, 14.4) & $19.5(16.1,23.4)$ & $36.3(28.3,45.5)$ \\
\hline Mean oxygen saturation (\%) & $94.0(92.9,95.1)$ & $94.4(93.2,95.4)$ & $93.8(92.9,94.9)$ & $93.4(92.4,94.6)$ & $93.4(92.2,94.4)$ \\
\hline Lowest oxygen saturation (\%) & $86.0(82.0,89.0)$ & $88.0(85.0,90.0)$ & $86.0(82.0,88.0)$ & $82.0(78.0,86.0)$ & $80.0(74.0,85.0)$ \\
\hline $\begin{array}{l}\text { \% Time spent with Oxygen Saturation } \\
<90 \%\end{array}$ & $0.6(0.0,3.7)$ & $0.1(0.0,1.0)$ & $0.8(0.2,3.1)$ & $2.5(0.4,6.1)$ & $5.7(1.1,11.4)$ \\
\hline \multicolumn{6}{|l|}{ NREM Sleep Period (\%) } \\
\hline $\mathrm{NI}$ & $13.9(10.2,18.3)$ & $13.6(9.8,16.9)$ & $13.1(9.4,16.4)$ & $16.2(\mid 1.7,20.8)$ & $16.6(12.4,23.2)$ \\
\hline N2 & $55.6(49.5,60.7)$ & $56.7(50.7,61.6)$ & $54.6(49.1,59.6)$ & $54.6(47.5,59.8)$ & $53.6(46.5,60.9)$ \\
\hline N3 & $15.4(9.2,20.8)$ & $14.8(8.5,19.9)$ & $17.0(12.1,22.1)$ & $14.3(9.6,19.9)$ & $14.7(6.8,21.8)$ \\
\hline REM sleep period (\%) & $14.6(11.4,18.0)$ & $14.8(11.6,17.9)$ & $14.9(11.8,17.8)$ & $14.6(\mid 1.2,18.5)$ & $12.7(8.7,17.5)$ \\
\hline \multicolumn{6}{|c|}{ Pittsburgh Sleep Quality Index, Mean +/ SD } \\
\hline Total score & $5.8 \pm 3.4$ & $5.8 \pm 3.2$ & $5.4 \pm 3.2$ & $6.1 \pm 4.0$ & $6.3 \pm 3.6$ \\
\hline
\end{tabular}

Notes: The analytical sample $(n=753)$ excludes 84 participants on sleep disrupting medications recorded on the night of the sleep study including benzodiazepines, opiates, nicotine replacement therapy, anti-psychotics, anti-depressants. Values represent mean \pm standard deviation or number (percentage) for categorical variables. Total numbers for each demographic may not correspond to reported number due to small missing values. Units are displayed in brackets. *Myocardial Infarction, Angina, Stroke, Transient Ischemic Attack. $\ddagger A H I_{R E M}$ : Rapid eye movement sleep (REM) AHI is calculated for participants with at least 30 minutes of REM sleep.

Abbreviation: $A \mathrm{HI}_{\mathrm{NREM}}$, non-rapid eye movement sleep $\mathrm{AHI}$. 
Table 2 Multiple Linear Regression Analyses of the Association Between Measures of Nocturnal Hypoxemia and Lipid Profiles in Men $\left(n=728^{\S}\right)$

\begin{tabular}{|c|c|c|c|c|}
\hline & \multicolumn{2}{|c|}{ Unadjusted Model $n=728$} & \multicolumn{2}{|c|}{ Covariate Adjusted Model* $n=663$} \\
\hline & B (SE) & $p$ value & B (SE) & $p$ value \\
\hline \multicolumn{5}{|l|}{ Apnea-Hypopnea Index } \\
\hline Triglycerides & $0.004(0.004)$ & 0.35 & $0.002(0.003)$ & 0.47 \\
\hline $\mathrm{HDL}$ & $-0.00 I(0.001)$ & 0.21 & $0.000(0.001)$ & 0.55 \\
\hline LDL & $-0.002(0.003)$ & 0.38 & $0.000(0.003)$ & 0.90 \\
\hline Total Cholesterol & $-0.002(0.003)$ & 0.49 & $0.001(0.003)$ & 0.82 \\
\hline \multicolumn{5}{|l|}{ ODI } \\
\hline Triglycerides & $0.004(0.005)$ & 0.37 & $0.001(0.003)$ & 0.61 \\
\hline HDL & $-0.001(0.001)$ & 0.13 & $0.001(0.001)$ & 0.48 \\
\hline LDL & $-0.00 I(0.003)$ & 0.78 & $0.002(0.003)$ & 0.53 \\
\hline Total Cholesterol & $0.000(0.003)$ & 0.93 & $0.002(0.003)$ & 0.49 \\
\hline \multicolumn{5}{|l|}{$\mathrm{AHI}_{\mathrm{REM}}{ }^{\ddagger}$} \\
\hline Triglycerides & $-0.002(0.004)$ & 0.57 & $-0.002(0.002)$ & 0.44 \\
\hline HDL & $-0.001(0.001)$ & 0.22 & $0.001(0.001)$ & 0.32 \\
\hline LDL & $-0.001(0.002)$ & 0.62 & $0.000(0.003)$ & 0.87 \\
\hline Total Cholesterol & $-0.002(0.003)$ & 0.52 & $0.000(0.003)$ & 0.99 \\
\hline \multicolumn{5}{|l|}{$A H I_{\text {REM }}$ if $A H I_{N R E M}<10 / h r$} \\
\hline Triglycerides & $0.000(0.005)$ & 0.97 & $-0.002(0.005)$ & 0.65 \\
\hline $\mathrm{HDL}$ & $-0.001(0.002)$ & 0.74 & $0.000(0.002)$ & 0.45 \\
\hline LDL & $-0.004(0.005)$ & 0.44 & $-0.003(0.006)$ & 0.65 \\
\hline Total Cholesterol & $-0.004(0.006)$ & 0.47 & $-0.003(0.007)$ & 0.65 \\
\hline
\end{tabular}

Notes: *Adjusted for age, smoking, depression, alcohol risk, total sleep time, HbAlc, diet quality, waist circumference. ${ }^{\S} \mathrm{Analyses}$ excluded participants using sleep disrupting medications recorded on the night of the PSG study include benzodiazepines, opiates, nicotine replacement therapy, anti-psychotics, anti-depressants. ${ }^{\ddagger} \mathrm{AHI} \mathrm{REM}{ }$ Rapid eye movement sleep (REM) AHI is calculated for participants with at least 30 minutes of REM sleep. In models excluding participants with AHI NREM $^{<} 10$, unadjusted models $n=339$; adjusted model $n=312$.

Abbreviations: $\mathrm{AHI}_{\mathrm{NREM}}$, non-rapid eye movement sleep $\mathrm{AHI}$.

hypertension, ${ }^{7,45}$ cardiovascular disease, ${ }^{46,47}$ and glycemic control in type 2 diabetes. ${ }^{48}$ In the current study, we were unable to demonstrate a separate contribution of $\mathrm{AHI}_{\mathrm{REM}}$ independent of $\mathrm{AHI}_{\mathrm{NREM}}$ to triglyceride levels. There may be a few reasons for this; REM sleep comprised only $15 \%$ of the sleep time in our study, there may be insufficient hypoxic burden present overall if significant OSA is not present in NREM sleep. Furthermore, to allow adequate observation of REM sleep, we excluded subjects with less than 30 min of REM sleep from $\mathrm{AHI}_{\mathrm{REM}}$ analyses. This may have excluded participants most at risk of chronic intermittent hypoxia-related lipid abnormalities given that severe OSA, or a high frequency of OSA arousals during the REM period will result in very short REM sleep.

Our findings regarding $\mathrm{AHI}_{\mathrm{REM}}$ are consistent with a recent clinical cohort study by $\mathrm{Xu}$ et $\mathrm{al}^{49}$ showing that associations of $\mathrm{AHI}_{\mathrm{REM}}$ with increasing serum triglyceride concentration were not independent of $\mathrm{AHI}_{\text {NREM }}$. A small study (15 participants) undertaken in
Hungary showed that serum lipid profiles were not adversely affected by the presence of REM predominant OSA. $^{50}$

Our findings also support other small clinic-based patient samples where OSA has been shown to be independently associated with serum triglyceride concentrations in individuals with $\mathrm{BMI}<30 \mathrm{Kg} / \mathrm{m}^{2},{ }^{23}$ and in patients with both normal BMI and normal waist circumference levels), ${ }^{25,26}$ but not with obesity. ${ }^{51}$ Of lean patients assessed as having OSA (AHI $>5 / \mathrm{hr}$ and relevant symptoms), $39.6 \%$ had multiple metabolic abnormalities, including serum triglycerides $\geq 1.7 \mathrm{mmol} / \mathrm{L} .{ }^{26}$ In studies of lean participants ${ }^{25,52}$ with varying severities of OSA ranging from mostly mild, ${ }^{44}$ to mild to severe OSA, ${ }^{40}$ compared to the control patients without OSA, those with OSA were significantly more likely to demonstrate impaired glucose metabolism and insulin resistance.

Animal studies provide evidence for a mechanism linking $\mathrm{CIH}$ and lipid abnormalities. In mice, $\mathrm{CIH}$, as occurs in 
Table 3 Multiple Linear Regression Analyses of the Association Between Nocturnal Hypoxemia Measures and Lipid Profiles in Men without Use of Lipid Lowering Therapies or Sleep Disrupting Medications ${ }^{\S}(n=566)$

\begin{tabular}{|c|c|c|c|c|}
\hline & \multicolumn{2}{|c|}{ Unadjusted Model $n=566$} & \multicolumn{2}{|c|}{ Covariate Adjusted Model* $n=517$} \\
\hline & B (SE) & $p$ value & B (SE) & $p$ value \\
\hline Apnea-Hypopnea Index (AHI) & & & & \\
\hline Triglycerides & $0.004(0.003)$ & 0.12 & $0.003(0.003)$ & 0.36 \\
\hline HDL & $-0.00 I(0.00 I)$ & 0.24 & $0.000(0.001)$ & 0.78 \\
\hline LDL & $0.001(0.003)$ & 0.64 & $0.001(0.003)$ & 0.65 \\
\hline Total Cholesterol & $0.002(0.003)$ & 0.60 & $0.00 I(0.003)$ & 0.64 \\
\hline ODI & & & & \\
\hline Triglycerides & $0.006(0.003)$ & 0.069 & $0.002(0.003)$ & 0.47 \\
\hline $\mathrm{HDL}$ & $-0.002(0.001)$ & 0.096 & $0.000(0.001)$ & 0.85 \\
\hline LDL & $0.002(0.003)$ & 0.48 & $0.002(0.003)$ & 0.48 \\
\hline Total Cholesterol & $0.002(0.003)$ & 0.48 & $0.002(0.004)$ & 0.57 \\
\hline $\mathrm{AHI}_{\mathrm{REM}}{ }^{\ddagger}$ & & & & \\
\hline Triglycerides & $0.000(0.003)$ & 0.95 & $-0.004(0.003)$ & 0.19 \\
\hline $\mathrm{HDL}$ & $0.000(0.001)$ & 0.81 & $0.002(0.001)$ & 0.081 \\
\hline LDL & $0.001(0.002)$ & 0.66 & $0.000(0.003)$ & 0.86 \\
\hline Total Cholesterol & $0.001(0.003)$ & 0.71 & $0.000(0.003)$ & 0.99 \\
\hline$A H I_{\text {REM }}$ if $A H I_{N R E M}<10 / h r$ & & & & \\
\hline Triglycerides & $-0.001(0.006)$ & 0.88 & $-0.002(0.006)$ & 0.79 \\
\hline $\mathrm{HDL}$ & $0.001(0.002)$ & 0.96 & $0.001(0.002)$ & 0.70 \\
\hline LDL & $0.000(0.005)$ & 0.94 & $0.000(0.006)$ & 0.96 \\
\hline Total Cholesterol & $0.000(0.006)$ & 0.98 & $-0.00 \mathrm{I}(0.007)$ & 0.94 \\
\hline
\end{tabular}

Notes: *Adjusted for age, smoking, depression, alcohol risk, total sleep time, HbAlc, diet quality, waist circumference. ${ }^{\S}$ Sleep disrupting medications recorded on the night of the PSG study included benzodiazepines, opiates, nicotine replacement therapy, anti-psychotics, anti-depressants. ${ }^{\ddagger} \mathrm{AHI}$ REM: Rapid eye movement sleep (REM) $A H I$ is calculated for participants with at least 30 minutes of REM sleep. In models excluding participants with $A H I_{N R E M}<10$ unadjusted models $n=277$; adjusted model $n=255$.

Abbreviation: $\mathrm{AHI}_{\mathrm{NREM}}$, non-rapid eye movement sleep $\mathrm{AHI}$.

OSA, has been shown to have adverse effects on lipid metabolism including increasing hepatic triglyceride production, decreasing plasma triglyceride clearance by lipase activity inhibition and increased free fatty acid mobilization from adipose tissue. ${ }^{15,53} \mathrm{Li}$ et al found that lean, but not obese mice, with pre-existing abnormalities of lipid metabolism, exposed to intermittent hypoxia exhibited upregulation of key transcription factors involved in triglyceride biosynthesis (SREBP - sterol regulatory element-binding protein, SCD-1- SREBP-1 regulated enzyme for lipid biosynthesis). ${ }^{54}$ Insulin inhibits hepatic triglyceride production and animal studies have also demonstrated a link between intermittent hypoxia and insulin resistance in lean mice. ${ }^{55,56}$ In human studies, Koenig et $\mathrm{al}^{27}$ recently reported large overnight CIH-related increases in plasma triglycerides that occurred in non-obese participants with OSA compared to participants with obesity and OSA (214.7 \pm 40.9 cf $95.6 \pm 12.6 \mathrm{mg} / 100 \mathrm{~mL}$ ), and speculate that muscle or liver free fatty acid uptake capacity may be exceeded by overnight increases in circulating FFAs and may therefore be associated with re-esterification of FFAs. In a small clinical study of 15 "healthy" men with severe OSA (mean WC: $97 \mathrm{~cm}$, BMI: $28.4 \mathrm{~kg} / \mathrm{m}^{2}$; free of significant comorbidities), Drager et $\mathrm{al}^{57}$ reported disturbances in triglyceride-rich lipoprotein metabolism, with correction of delayed fractional clearance rates (FCR) of radiolabeled triglycerides and cholesteryl ester by 3 months of CPAP therapy supporting their earlier work. ${ }^{15}$ That disrupted sleep that occurs in OSA is linked to dyslipidemia is further supported by a recent multi-ancestry genome-wide sleepby-single nucleotide polymorphism (SNP) analyses on three lipid traits (HDL, LDL, and triglycerides) which identified gene-short sleep interactions that explained $4.25 \%$ of the variance in triglyceride levels. ${ }^{58}$

We therefore suggest based upon our data and the results of animal and mechanistic studies that intermittent hypoxia due to OSA may induce metabolic derangements associated with insulin resistance that cannot be separated from the predominant effect of visceral obesity and therefore results are observed in lean participants where obesity 

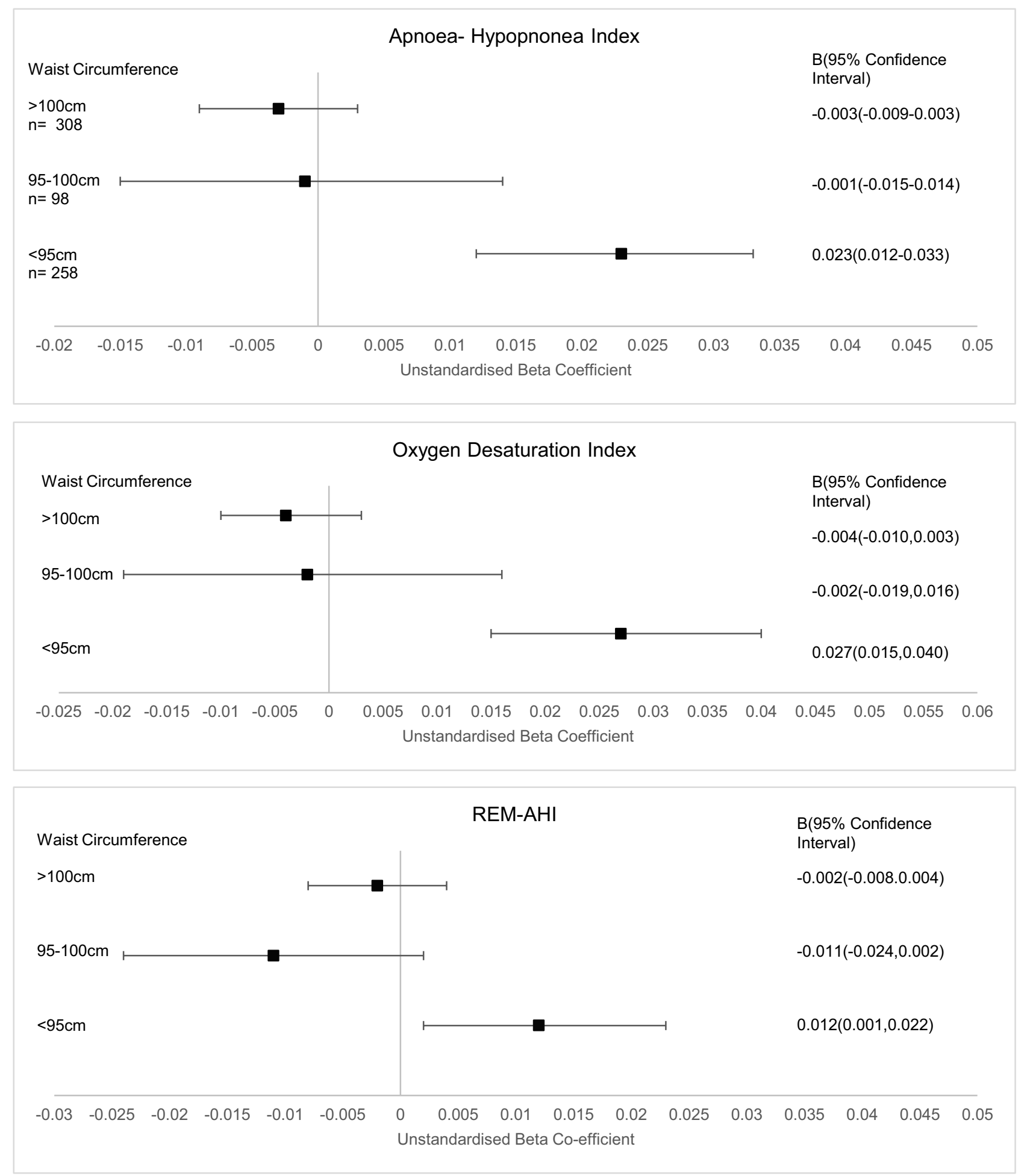

Figure 2 Forest plots for the association between triglycerides and AHI, REM-AHI and ODI in males separated into groups by waist circumference $(<95 \mathrm{~cm}, 95-100 \mathrm{~cm}$, $>100 \mathrm{~cm}$ ). Coefficients are unstandardized with $95 \%$ confidence intervals. Model adjusted for age, smoking, depression, alcohol risk, total sleep time, HbAlc, diet quality. Sleep disrupting medications include benzodiazepines, opiates, nicotine replacement therapy, anti-psychotics, anti-depressants. 
does not have a dominant effect. Supporting this, CPAP therapy has resulted in an improvement in insulin resistance in non-obese participants to a greater effect than in obese participants. ${ }^{59}$

The current study has several strengths. The participants were randomly recruited, community-dwelling men with extensive phenotypic, clinical, and biochemical assessments. They were broadly representative of the Australian male population aged 40 and over. The sleep subgroup was randomly selected from the whole study population, had similar socio-demographic and healthrelated characteristics to the full sample and gold standard polysomnography was performed in-home. ${ }^{28}$ We adjusted for co-founders that were clinically relevant or showed strong significance in univariate analysis, and we performed sensitivity analysis excluding the use of lipid lowering agents. The cross-sectional nature of the study limits any inferences about causality, and the findings cannot be generalized to younger men or women. Sex-specific relationships between OSA and serum lipid profiles have previously been reported. ${ }^{60}$ Furthermore, our findings from a cohort of community-dwelling men with many reporting few symptoms may not be generalizable to patients in the clinical setting. However, the advantage of populationbased studies is the ability to identify healthy weight, asymptomatic individuals with OSA and cardiometabolic risk who would otherwise be unlikely to be referred for a sleep study.

Our findings have potential clinical implications. OSA has been shown to occur in approximately $5-14 \%$ of lean men $^{61}$ who may be perceived as being at low risk of OSA and its related cardiometabolic sequelae. The presence of obstructive sleep apnea should be considered in the workup for elevated serum triglycerides in lean men. A recent clinical study reported high prevalence rates of metabolic risk in lean patients with OSA (AHI $>5 / \mathrm{hr}$, BMI $<25 \mathrm{~kg} / \mathrm{m}^{2}$ and waist $<80 \mathrm{~cm}$ in females; $<90 \mathrm{~cm}$ in males), with dyslipidemia demonstrated in $61 \%$, and two of three metabolic syndrome components in $64 \% .^{62}$ Despite this high metabolic risk, treatment of hyperlipidemia in clinical populations with OSA is not high [eg $12 \%$ in the European Sleep Apnea Database Cohort (ESADA) cohort]. ${ }^{20}$

OSA treatment with continuous positive airway pressure (CPAP) therapy, however, may not yield desired reductions in lipid levels and mainstay therapy with HMGCoA reductase inhibitors and fibrates will be required. As reviewed recently, ${ }^{18,63}$ observational studies and randomized controlled trials (often limited by small sample sizes and short follow-up times) have reported inconsistent effects of CPAP therapy on lipid parameters. In the ESADA Cohort, where higher ODI and AHI were associated with lipid parameters, ${ }^{20,21}$ an observational study of at least 3 months of PAP therapy $(n=1564)$ in the cohort yielded a mean decrease in total cholesterol of $4.9 \mathrm{mg} / \mathrm{dl}$ $(0.13 \mathrm{mmol} / \mathrm{L})$ after $\geq 3$ months therapy, with no effect on triglyceride levels. ${ }^{64}$ Compliance with CPAP therapy may have influenced the inconsistent benefits on lipid parameters reported in studies to date as CPAP use less than 4hrs per night is unlikely to treat REM sleep OSA demonstrated in our study and others to be relevant for lipid measures. ${ }^{49}$

In conclusion, we have shown that in a population of community-dwelling male adults, severe obstructive sleep apnea is a risk factor for raised serum triglyceride concentrations in those without central adiposity. This is likely the direct consequence of chronic intermittent hypoxia on triglyceride metabolism. Good CPAP compliance over the entire night including REM sleep may be beneficial. Further studies are required to evaluate the relationships between OSA and dyslipidemia in lean women and in younger men and to determine the effects of CPAP on triglycerides.

\section{Acknowledgments}

This work was conducted at the University of Adelaide. The authors wish to acknowledge the participants of the study for their ongoing contributions to the project.

\section{Funding}

This work was supported by a National Health and Medical Research Council of Australia Project Grant (627227), the Hospital Research Foundation and ResMed Foundation.

\section{Disclosure}

Dr Sarah L Appleton reports grants from NH\&MRC of Australia and The Hospital Research Foundation Group, during the conduct of the study; personal fees from Dove Press, outside the submitted work. Professor Robert J Adams reports grants from National Health and Medical Research Council, The Hospital Research Foundation, ResMed Foundation, and National Heart Foundation, during the conduct of the study; grants from Philips, outside the submitted work. The authors report no other conflicts of interest in this work. 


\section{References}

1. Maspero C, Giannini L, Galbiati G, Rosso G, Farronato G. Obstructive sleep apnea syndrome: a literature review. Minerva Stomatol. 2015;64(2):97-109.

2. Heinzer R, Vat S, Marques-Vidal $P$, et al. Prevalence of sleep-disordered breathing in the general population: the HypnoLaus study. Lancet Respir Med. 2015;3(4):310-318. doi:10.1016/S2213-2600(15)00043-0

3. Heinzer R, Marti-Soler H, Haba-Rubio J. Prevalence of sleep apnoea syndrome in the middle to old age general population. Lancet Respir Med. 2016;4(2):e5-e6. doi:10.1016/S2213-2600(16)00006-0

4. Costa LE, Uchôa CHG, Harmon RR, Bortolotto LA, Lorenzi-Filho G, Drager LF. Potential underdiagnosis of obstructive sleep apnoea in the cardiology outpatient setting. Heart. 2015;101(16):1288-1292. doi:10.1136/heartjnl-2014-307276

5. Javaheri S, Barbe F, Campos-Rodriguez F, et al. Sleep apnea: types, mechanisms, and clinical cardiovascular consequences. $J$ Am Coll Cardiol. 2017;69(7):841-858. doi:10.1016/j.jacc.2016.11.069

6. Gonzaga C, Bertolami A, Bertolami M, Amodeo C, Calhoun D. Obstructive sleep apnea, hypertension and cardiovascular diseases. J Hum Hypertens. 2015;29(12):705-712. doi:10.1038/jhh.2015.15

7. Appleton SL, Vakulin A, Martin SA, et al. Hypertension is associated with undiagnosed OSA during rapid eye movement sleep. Chest. 2016;150(3):495-505. doi:10.1016/j.chest.2016.03.010

8. Chami HA, Gottlieb DJ, Redline S, Punjabi NM. Association between glucose metabolism and sleep-disordered breathing during REM sleep. Am J Respir Crit Care Med. 2015;192(9):1118-1126. doi:10.1164/rccm.201501-0046OC

9. Hirotsu C, Haba-Rubio J, Togeiro SM, et al. Obstructive sleep apnoea as a risk factor for incident metabolic syndrome: a joined Episono and HypnoLaus prospective cohorts study. Eur Respir J. 2018;52:5 doi:10.1183/13993003.01150-2018

10. Zhao YY, Javaheri S, Wang R, et al. Associations between sleep apnea and subclinical carotid atherosclerosis. Stroke. 2019;50 (12):3340-3346. doi:10.1161/STROKEAHA.118.022184

11. Dematteis M, Julien C, Guillermet C, et al. Intermittent hypoxia induces early functional cardiovascular remodeling in mice. $\mathrm{Am}$ $J$ Respir Crit Care Med. 2008;177(2):227-235. doi:10.1164/ rccm.200702-2380C

12. Lavie L. Obstructive sleep apnoea syndrome-an oxidative stress disorder. Sleep Med Rev. 2003;7(1):35-51. doi:10.1053/ smrv.2002.0261

13. Arnaud C, Bochaton T, Pépin J-L, Belaidi E. Obstructive sleep apnoea and cardiovascular consequences: pathophysiological mechanisms. Arch Cardiovasc Dis. 2020;113(5):350-358. doi:10.1016/j.acvd.2020.01.003

14. Lévy P, Ryan S, Oldenburg O, Parati G. Sleep apnoea and the heart. Eur Respir Rev. 2013;22(129):333-352. doi:10.1183/09059180.00004513

15. Drager LF, Li J, Shin M-K, et al. Intermittent hypoxia inhibits clearance of triglyceride-rich lipoproteins and inactivates adipose lipoprotein lipase in a mouse model of sleep apnoea. Eur Heart $J$. 2012;33(6):783-790. doi:10.1093/eurheartj/ehr097

16. Drager LF, Jun J, Polotsky VY. Obstructive sleep apnea and dyslipidemia: implications for atherosclerosis. Curr Opin Endocrinol Diabetes Obes. 2010;17(2):161-165. doi:10.1097/ MED.0b013e 3283373624

17. Adedayo AM, Olafiranye O, Smith D, et al. Obstructive sleep apnea and dyslipidemia: evidence and underlying mechanism. Sleep Breath. 2014;18(1):13-18. doi:10.1007/s11325-012-0760-9

18. Barros D, García-Río F. Obstructive sleep apnea and dyslipidemia: from animal models to clinical evidence. Sleep. 2019;42:3. doi:10.1093/sleep/zsy236

19. Trzepizur W, Le Vaillant M, Meslier N, et al. Independent association between nocturnal intermittent hypoxemia and metabolic dyslipidemia. Chest. 2013;143(6):1584-1589. doi:10.1378/chest.12-1652
20. Gunduz C, Basoglu OK, Hedner J, et al. Hyperlipidaemia prevalence and cholesterol control in obstructive sleep apnoea: data from the European sleep apnea database (ESADA). J Intern Med. 2019;286 (6):676-688. doi:10.1111/joim.12952

21. Gündüz C, Basoglu OK, Hedner J, et al. Obstructive sleep apnoea independently predicts lipid levels: data from the European Sleep Apnea Database. Respirology. 2018;23(12):1180-1189. doi:10.1111/ resp. 13372

22. Martínez-Cerón E, Casitas R, Galera R, et al. Contribution of sleep characteristics to the association between obstructive sleep apnea and dyslipidemia. Sleep Med. 2021;84:63-72. doi:10.1016/j. sleep.2021.05.012

23. Karkinski D, Georgievski O, Dzekova-Vidimliski P, Milenkovic T, Dokic D. Obstructive sleep apnea and lipid abnormalities. Open Access Maced J Med Sci. 2017;5(1):19-22. doi:10.3889/oamjms.2017.011

24. Schwartz AR, Patil SP, Laffan AM, Polotsky V, Schneider H, Smith PL. Obesity and obstructive sleep apnea. Proc Am Thorac Soc. 2008;5(2):185-192. doi:10.1513/pats.200708-137MG

25. Lin Q-C, Zhang X-B, Chen G-P, Huang D-Y, Din H-B, Tang A-Z. Obstructive sleep apnea syndrome is associated with some components of metabolic syndrome in nonobese adults. Sleep Breath. 2012;16(2):571-578. doi:10.1007/s11325-011-0544-7

26. Akahoshi T, Uematsu A, Akashiba T, et al. Obstructive sleep apnoea is associated with risk factors comprising the metabolic syndrome. Respirology. 2010;15(7):1122-1126. doi:10.1111/j.14401843.2010.01818.x

27. Koenig AM, Koehler U, Hildebrandt O, et al. The effect of obstructive sleep apnea and continuous positive airway pressure therapy on skeletal muscle lipid content in obese and nonobese men. $J$ Endocr Soc. 2021;5(8):bvab082. doi:10.1210/jendso/bvab082

28. Grant JF, Martin SA, Taylor AW, et al. Cohort profile: the Men Androgen Inflammation Lifestyle Environment and Stress (MAILES) Study. Int $J$ Epidemiol. 2014;43(4):1040-1053. doi:10.1093/ije/dyt064

29. Buysse DJ, Reynolds CF, Monk TH, Berman SR, Kupfer DJ. The Pittsburgh Sleep Quality Index: a new instrument for psychiatric practice and research. Psychiatry Res. 1989;28(2):193-213.

30. Johns MW. A New Method for measuring daytime sleepiness: the Epworth Sleepiness Scale. Sleep. 1991;14(6):540-545. doi:10.1093/ sleep/14.6.540

31. Thornton AT, Ruehland WR, Duce B, et al. ASTA/ASA. Commentary on AASM manual for the scoring of sleep and associated events; 2010. Available from: https://sleep.org.au/Public/ Resource-Centre/F-Sleep-docs/ASTA-ASA-comm.aspx. Accessed September 24, 2021.

32. Ruehland WR, Rochford PD, O'Donoghue FJ, Pierce RJ, Singh P, Thornton AT. The new AASM criteria for scoring hypopneas: impact on the apnea hypopnea index. Sleep. 2009;32(2):150-157. doi:10.1093/sleep/32.2.150

33. Australian Institute of Health and Welfare (AIHW). The Active Australia Survey: A Guide and Manual for Implementation, Analysis and Reporting; 2003:55

34. WHO Collaborating Centre for Drug Statistics Methodology. Guidelines for ATC Classification and DDD Assignment, 2021. Oslo; 2020. Available from: https://scholar.google.com/scholar lookup?title $=$ Guidelines $\% 20$ for $\% 20 \mathrm{ATC} \% 20$ classification $\% 20$ and $\%$ 20DDD $\% 20$ assignment $\% 202010$ \&publication_year=2009. Accessed June 7, 2021.

35. Lewinsohn PM, Seeley JR, Roberts RE, Allen NB. Center for Epidemiologic Studies Depression Scale (CES-D) as a screening instrument for depression among community-residing older adults. Psychol Aging. 1997;12(2):277-287. doi:10.1037/0882-7974.12.2.277

36. Steer RA, Clark DA, Beck AT, Ranieri WF. Common and specific dimensions of self-reported anxiety and depression: the BDI-II versus the BDI-IA. Behav Res Ther. 1999;37(2):183-190. doi:10.1016/ S0005-7967(98)00087-4 
37. Cao Y, Taylor AW, Wittert G, Adams R, Shi Z. Dietary patterns and sleep parameters in a cohort of community dwelling Australian men. Asian Pac J Clin Nutr. 2017;26(6):1158-1169. doi:10.6133/ apjcn.122016.03

38. Hodge A, Patterson AJ, Brown WJ, Ireland P, Giles G. The Anti Cancer Council of Victoria FFQ: relative validity of nutrient intakes compared with weighed food records in young to middle-aged women in a study of iron supplementation. Aust N Z J Public Health. 2000;24 (6):576-583. doi:10.1111/j.1467-842x.2000.tb00520.x

39. Xu C, Marchand NE, Driban JB, McAlindon T, Eaton CB, Lu B. Dietary patterns and progression of knee osteoarthritis: data from the osteoarthritis initiative. Am J Clin Nutr. 2020;111(3):667-676. doi:10.1093/ajen/nqz333

40. Czernichow S, Kengne A-P, Huxley RR, et al. Comparison of waist-to-hip ratio and other obesity indices as predictors of cardiovascular disease risk in people with type-2 diabetes: a prospective cohort study from ADVANCE. Eur J Cardiovasc Prev Rehabil. 2011;18(2):312-319. doi:10.1097/HJR.0b013e32833c1aa3

41. Lemieux I, Pascot A, Couillard C, et al. Hypertriglyceridemic waist. Circulation. 2000;102(2):179-184. doi:10.1161/01.CIR.102.2.179

42. Findley LJ, Wilhoit SC, Suratt PM. Apnea duration and hypoxemia during REM sleep in patients with obstructive sleep apnea. Chest. 1985;87(4):432-436. doi:10.1378/chest.87.4.432

43. Mokhlesi B, Varga AW. Obstructive sleep apnea and cardiovascular disease. REM sleep matters! Am J Respir Crit Care Med. 2018;197 (5):554-556. doi:10.1164/rccm.201710-2147ED

44. Varga AW, Mokhlesi B. REM obstructive sleep apnea: risk for adverse health outcomes and novel treatments. Sleep Breath. 2019;23(2):413-423. doi:10.1007/s11325-018-1727-2

45. Mokhlesi B, Finn LA, Hagen EW, et al. Obstructive sleep apnea during REM sleep and hypertension. results of the Wisconsin Sleep Cohort. Am J Respir Crit Care Med. 2014;190(10):1158-1167. doi:10.1164/rccm.201406-1136OC

46. Aurora RN, Crainiceanu C, Gottlieb DJ, Kim JS, Punjabi NM. Obstructive sleep apnea during REM sleep and cardiovascular disease. Am J Respir Crit Care Med. 2018;197(5):653-660. doi:10.1164/rccm.201706-1112OC

47. Ljunggren M, Lindberg E, Franklin KA, et al. Obstructive sleep apnea during rapid eye movement sleep is associated with early signs of atherosclerosis in women. Sleep. 2018;41:7. doi:10.1093/sleep/zsy099

48. Grimaldi D, Beccuti G, Touma C, Van Cauter E, Mokhlesi B. Association of obstructive sleep apnea in rapid eye movement sleep with reduced glycemic control in type 2 diabetes: therapeutic implications. Diabetes Care. 2014;37(2):355-363. doi:10.2337/dc13-0933

49. Xu H, Xia Y, Li X, et al. Association between obstructive sleep apnea and lipid metabolism during REM and NREM sleep. $J$ Clin Sleep Med. 2020;16(4):475-482. doi:10.5664/jcsm.8242

50. Bikov A, Lazar Z, Horvath P, et al. Association between serum lipid profile and obstructive respiratory events during REM and non-REM sleep. Lung. 2019;197(4):443-450. doi:10.1007/s00408-019-00195-7

51. Sharma SK, Kumpawat S, Goel A, Banga A, Ramakrishnan L, Chaturvedi P. Obesity, and not obstructive sleep apnea, is responsible for metabolic abnormalities in a cohort with sleep-disordered breathing. Sleep Med. 2007;8(1):12-17. doi:10.1016/j.sleep.20 06.06 .014
52. Pamidi S, Wroblewski K, Broussard J, et al. Obstructive sleep apnea in young lean men: impact on insulin sensitivity and secretion. Diabetes Care. 2012;35(11):2384-2389. doi:10.2337/dc12-0841

53. Jun JC, Shin M-K, Yao Q, et al. Acute hypoxia induces hypertriglyceridemia by decreasing plasma triglyceride clearance in mice. $\mathrm{Am}$ J Physiol Endocrinol Metab. 2012;303(3):E377-E388. doi:10.1152/ ajpendo.00641.2011

54. Li J, Thorne LN, Punjabi NM, et al. Intermittent hypoxia induces hyperlipidemia in lean mice. Circ Res. 2005;97(7):698-706. doi:10.1161/01.RES.0000183879.60089.a9

55. Iiyori $\mathrm{N}$, Alonso LC, Li J, et al. Intermittent hypoxia causes insulin resistance in lean mice independent of autonomic activity. $\mathrm{Am}$ $J$ Respir Crit Care Med. 2007;175(8):851-857. doi:10.1164/ rccm.200610-1527OC

56. Wang N, Khan SA, Prabhakar NR, Nanduri J. Impairment of pancreatic $\beta$-cell function by chronic intermittent hypoxia. Exp Physiol. 2013;98(9):1376-1385. doi:10.1113/expphysiol.2013.072454

57. Drager LF, Tavoni TM, Silva VM, et al. Obstructive sleep apnea and effects of continuous positive airway pressure on triglyceride-rich lipoprotein metabolism. J Lipid Res. 2018;59(6):1027-1033. doi:10.1194/j1r.M083436

58. Noordam R, Bos MM, Wang H, et al. Multi-ancestry sleep-by-SNP interaction analysis in 126,926 individuals reveals lipid loci stratified by sleep duration. Nat Commun. 2019;10(1):1-13. doi:10.1038/ s41467-019-12958-0

59. Harsch IA, Schahin SP, Radespiel-Tröger M, et al. Continuous positive airway pressure treatment rapidly improves insulin sensitivity in patients with obstructive sleep apnea syndrome. Am J Respir Crit Care Med. 2004;169(2):156-162. doi:10.1164/rccm.200302-206OC

60. Newman AB, Nieto FJ, Guidry U, et al. Relation of sleep-disordered breathing to cardiovascular disease risk factors the sleep heart health study. Am J Epidemiol. 2001;154(1):50-59. doi:10.1093/aje/154.1.50

61. Peppard PE, Young T, Barnet JH, Palta M, Hagen EW, Hla KM. Increased prevalence of sleep-disordered breathing in adults. $\mathrm{Am}$ $J$ Epidemiol. 2013;177(9):1006-1014. doi:10.1093/aje/kws342

62. Chaudhary P, Goyal A, Pakhare A, et al. Metabolic syndrome in non-obese patients with OSA: learning points of a cross-sectional study from a tertiary care hospital in Central India. Sleep Breath. 2021. doi:10.1007/s11325-021-02401-4

63. Jullian-Desayes I, Joyeux-Faure M, Tamisier R, et al. Impact of obstructive sleep apnea treatment by continuous positive airway pressure on cardiometabolic biomarkers: a systematic review from sham CPAP randomized controlled trials. Sleep Med Rev. 2015;21:23-38. doi:10.1016/j.smrv.2014.07.004

64. Gunduz C, Basoglu OK, Kvamme JA, et al. Long-term positive airway pressure therapy is associated with reduced total cholesterol levels in patients with obstructive sleep apnea: data from the European Sleep Apnea Database (ESADA). Sleep Med. 2020;75:201-209. doi:10.1016/j.sleep.2020.02.023
Nature and Science of Sleep

\section{Publish your work in this journal}

Nature and Science of Sleep is an international, peer-reviewed, open access journal covering all aspects of sleep science and sleep medicine, including the neurophysiology and functions of sleep, the genetics of sleep, sleep and society, biological rhythms, dreaming, sleep disorders and therapy, and strategies to optimize healthy sleep.
The manuscript management system is completely online and includes a very quick and fair peer-review system, which is all easy to use. Visit http://www.dovepress.com/testimonials.php to read real quotes from published authors. 